TERRA. Revista de Desarrollo Local

e-ISSN: 2386-9968

Número 7 (2020), 329-339

DOI 10.7203/terra.7.19285

IIDL - Instituto Interuniversitario de Desarrollo Local

\title{
Reseña. La sociedad sin relato. Antropología y estética de la inminencia
}

\section{Elvira Calle Sánchez}

Licenciada en Historia del Arte (Universidad de Valencia) y Máster en Gestión del Patrimonio Cultural (Universidad de Zaragoza)

ecallesanchez@gmail.com

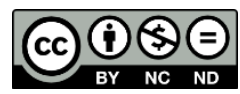

Esta obra se distribuye con la licencia Creative Commons

Reconocimiento-NoComercial-SinObraDerivada 4.0 Internacional 


\section{SECCIÓN RESEÑAS}

\section{Reseña. La sociedad sin relato. Antropología y estética de la inminencia}

Resumen: El siglo XXI comenzó dos veces: el 11 de septiembre de 2001, la caída de las Torres Gemelas impuso en la escena política y mediática un desplazamiento pues pasamos del multiculturalismo entendido como reconocimiento de las diferencias dentro de cada nación a los conflictos interculturales en una geopolítica global donde todas las sociedades somos interdependientes; y el 15 de septiembre de 2008, cuando la quiebra de Lehman Brothers vino a sacudir esta agenda política y cultural, llevando a su cumbre dramática el desorden neoliberal en varios continentes. Estos acontecimientos nos han dejado ante la perspectiva de un mundo sin promesas y han hecho de este siglo el gran territorio de la incertidumbre. En este contexto en el que las ciencias sociales hallan difícil explicar los logros y los fracasos de la globalización, Canclini considera que una nueva mirada sobre el arte puede ayudar a comprender las grandes encrucijadas de la sociedad. ¿Qué dicen sobre esta época los desplazamientos de las prácticas artísticas basadas en objetos a prácticas artísticas basadas en contextos, hasta llegar a insertar las obras en medios de comunicación, espacios urbanos, redes digitales y formas de participación social? No hay un relato para la sociedad globalizada que articule sin conflictos los desacuerdos disciplinarios, sociales e interculturales pero el arte que trabaja con la inminencia se ha mostrado fecundo para elaborar una pregunta distinta: ¿qué hacen las sociedades con aquello para lo que no encuentran respuesta en la cultura, la política y la tecnología?

Palabras clave: Sociedad sin relato, globalización, arte, estética, antropología.

Recibido: 14 de diciembre de 2020

Devuelto para revisión: -

Aceptado: 15 de diciembre de 2020

\section{Referencia / Citation:}

Calle, E. (2020). Reseña. La sociedad sin relato. Antropología y estética de la inminencia. TERRA. Revista de Desarrollo Local, (7), 329-339. DOI 10.7203/terra.7.19285 
Néstor García Canclini

\section{LA SOCIEDAD SIN RELATO. ANTROPOLOGÍA Y ESTÉTICA DE LA INMINENCIA}

Madrid, Katz, 2011, 264 páginas

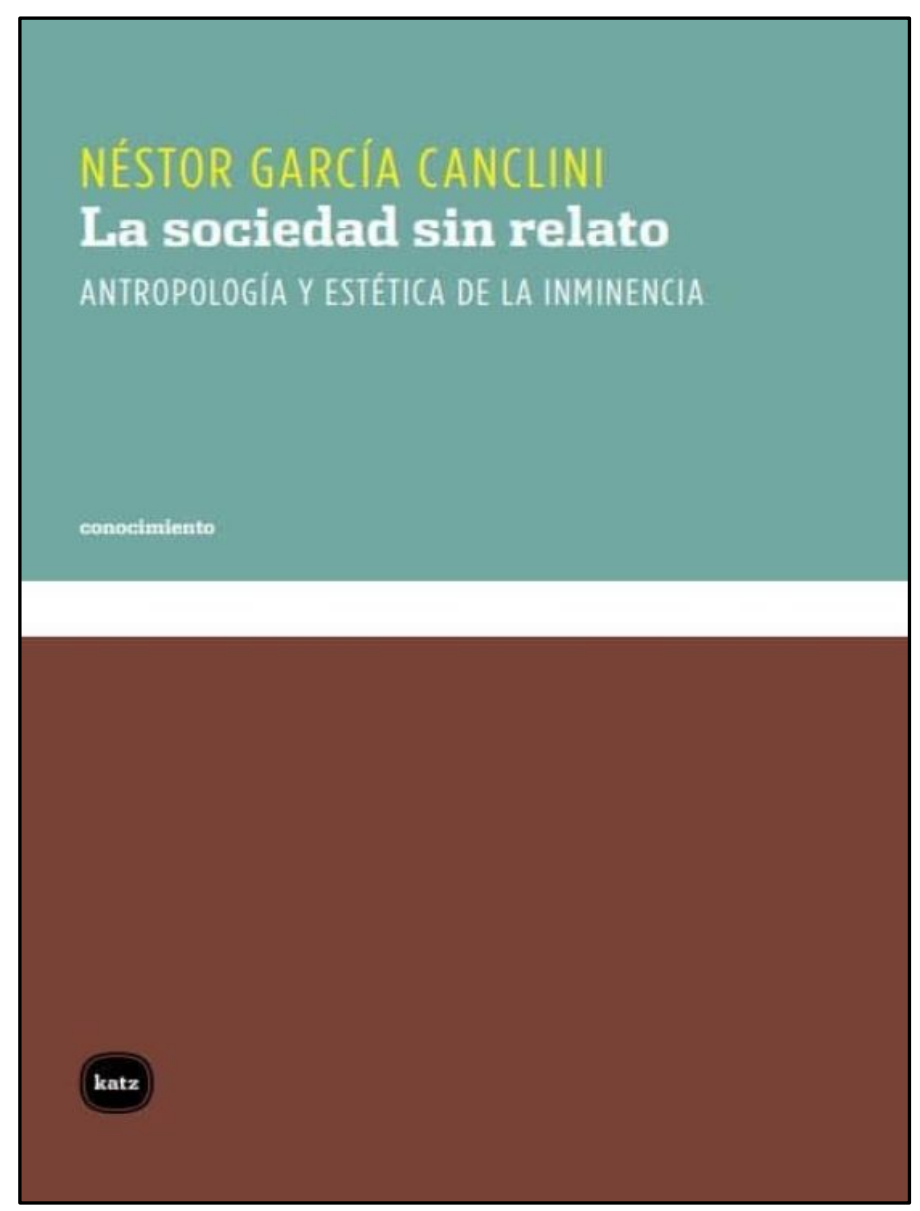

\section{El arte fuera de sí}

La muerte del arte se anunció muchas veces y sin embargo, en las últimas décadas, se ha convertido en laboratorio de experimentación intelectual en la sociología, la antropología, la filosofía y el psicoanálisis así como proveedor de diversas tácticas de distinción. Se le pide incluso que ocupe el lugar que dejó vacante la política y que proponga espacios colectivos de gestión intercultural.

Desde principios del siglo XX, la sociología mostró la necesidad de entender los movimientos artísticos en conexión con los procesos sociales. Ahora, esa implicación externa del arte es más visible debido al creciente valor económico y mediático alcanzado por numerosas obras. Para explicar este fenómeno, Canclini plantea la necesidad de mirar los nuevos papeles que asume el arte en la actualidad y que extienden su acción más allá de lo que se organiza como campo artístico. En concreto, plantea explicaciones vinculadas a los logros y fracasos de la globalización: las artes dramatizan la agonía de las utopías emancipadoras y renuevan las experiencias sensibles comunes en un mundo tan interconectado como dividido.

El siglo XX terminó sin paradigmas de desarrollo ni de explicación de la sociedad, solo se decía que contábamos con múltiples narrativas. Comenzamos el siglo XXI con dispersos relatos fragmentados. Y es que la última gran narrativa (occidental) auspiciada por la caída del Muro de Berlín en 1989 imaginó que habría un solo mundo con Estados Unidos como único centro y que su estilo de modernización capitalista volvería homogéneo el planeta. Este relato duró hasta la otra gran caída, la de las Torres Gemelas en 2001, que giró la mirada hacia los planteamientos de Samuel Huntington sobre la persistencia de civilizaciones en choque, el poder compartido del inglés con otras lenguas, y la multipolaridad económica y cultural. Ambas propuestas han tenido sus repercusiones en representaciones artísticas. Ante este panorama, Canclini habla de sociedad sin relato, no porque falten, como ocurría con el posmodernismo, sino porque ahora no existe ningún 
relato que organice la diversidad en un mundo cuya interdependencia hace desear a muchos que exista.

En este contexto, el autor plantea que el arte se volvió postautónomo: por un lado, se trata de un arte diseminado en una globalización que no logra articularse, y donde no es posible pensar ya en una historia con una sola orientación; y por otro, aumentan los desplazamientos de las prácticas artísticas basadas en objetos a prácticas artísticas basadas en contextos, hasta llegar a insertar las obras en medios de comunicación, espacios urbanos, redes digitales y formas de participación social donde parece diluirse la diferencia estética.

Asimismo, sitúa el arte en la inminencia: es decir que las obras no simplemente suspenden la realidad, sino que se sitúan en un momento previo, cuando lo real es posible, y tratan los hechos como acontecimientos que están a punto de ser. Plantea trabajar con esta hipótesis en un momento en el que la expansión del arte más allá de su propio campo supone que sus límites se están desdibujando al mezclarse con el desarrollo urbano, las industrias del diseño y el turismo.

\section{Estética y ciencias sociales: dudas convergentes}

Hablar de la situación de las artes cuando carecemos de teorías universalmente válidas tanto del arte como de la globalización no es un problema menor. Canclini hace un breve repaso de los distintos intentos de las teorías del arte por construir un saber universalmente válido.

Por un lado, la estética filosófica buscó universalizar su reflexión pero estaba asociada a la modernidad europea, la razón ilustrada y el romanticismo. Desde la sociología, Bourdieu no fue el primero en advertir que uno de los rasgos de la modernidad era la construcción de campos autónomos pero sí fue el sociólogo que construyó una teoría más sofisticada y rigurosa sobre las maneras en que el arte se separó de sus condicionamientos externos. Desde la antropología, autores como Becker, destacaron que el arte era una actividad cooperativa y que estudiarlo implicaba la necesidad de entender la obra en el contexto de su producción, circulación y apropiación. Sin embargo, las vanguardias del siglo XX al relativizar los valores estéticos y la fundación del gusto, admitieron la existencia de múltiples poéticas y con ello acabaron deconstruyendo el sentido autónomo del arte y el relato que había organizado sus vínculos con la política, el mercado y los medios.

Ante la dificultad de llegar a respuestas universalizables, en los últimos años prevalece la antropología (qué hacen quienes se llaman artistas) sobre las estéticas filosóficas (qué es el arte) y la semiótica (qué dice el arte y de qué estamos hablando cuando hablamos de arte). Así, se consolida un giro etnográfico en el estudio del arte y las prácticas artísticas, que en cierta medida implica simplificar la cuestión. Al centrarse en analizar de qué manera se comportan los que hacen arte, Canclini constata que nos encontramos en un giro transdisciplinario, intermedial y globalizado, que contribuye tanto a redefinir lo que entendíamos por arte en el Occidente moderno como en el Oriente preglobal.

Al mismo tiempo, las artes participan en la redefinición de las ciencias sociales, que también dudan de su identidad: la descomposición y las transiciones del capitalismo y la globalización las dejaron bruscamente sin certezas para definir sus objetos de estudio. Los antropólogos dudan de que su objeto de estudio pueda llamarse cultura, los museólogos no aciertan a exponer ese objeto que acumula tantas definiciones (tantas 
como arte), y los especialistas en patrimonio reinician cada año la tarea de justificar su defensa y preservación.

Ante esta situación, parece que pierde sentido buscar la esencia del arte, de la cultura o de la sociedad porque lo que denominamos como tal es construido de maneras distintas en cada país y en cada época. La tarea ahora es la de formular marcos analíticos que permitan comprender por qué y cómo se los construye de ese modo, y de qué manera funcionan o fallan.

\section{Culturas visuales: entre el arte y el patrimonio}

Cuando Benjamin, Borges y Merleau-Ponty escribieron textos delimitando los territorios del arte y la literatura existían museos pero no las numerosas bienales, y ferias de arte actuales, ni los mercados artísticos y literarios se entremezclaban con los medios, el turismo, la expansión y la descomposición urbana, las migraciones globales y la red digital. Entonces era más fácil valorar los gestos de los artistas y oponerlos a los museos y demás instituciones.

Las demarcaciones sociológicas del lugar de las artes en el mundo moderno (Bourdieu) también fueron desbordadas por las derivas recientes. Hoy, la práctica del arte, sus formas y su comunicación se modifican al interactuar los artistas plásticos con las tecnologías audiovisuales y digitales. Benjamin y Borges anticiparon los efectos tecnológicos sobre el arte: los deslices entre realidad y representaciones virtuales y los juegos entre originales y copias.

La discusión sobre la originalidad y la singularidad de ciertos bienes culturales se extiende a la sobrevaloración que cada etnia, clase o época hacen sobre lo propio. También aparece aunque de otro modo en los organismos y las doctrinas que, buscando superar el etnocentrismo, construyen criterios de jerarquización con pretensiones universales como ocurre con el programa de "Patrimonio de la Humanidad" de la UNESCO creado en 1972, que interesa al autor como un intento de organizar las diferencias, clasificar los objetos y los lugares, e intervenir en su difusión e interpretación.

La noción de patrimonio cultural abarca bienes materiales muy variados a los que, a principios de siglo XXI, la UNESCO agregó las manifestaciones de lo que llama "patrimonio cultural inmaterial": es decir, creaciones orales, saberes, rituales festivos y técnicas artesanales. Estos bienes, sin perjuicio de la soberanía o propiedad nacionales, constituyen un patrimonio universal en cuya protección la comunidad internacional entera tiene el deber de cooperar. En cuanto a los criterios de selección, en las primeras décadas se privilegió la "valorización estética" o la "autenticidad", luego se criticó el eurocentrismo de las decisiones y ahora se busca hacer visible la "pluralidad de las culturas". Para Canclini, sería más sencillo atribuir la condición de patrimonio de la Humanidad a la propia UNESCO, por su aspiración a ocuparse de lo que es común a todos, ya que según él la universalización es parcial y relativa a varios procesos de selección y exclusión, de difusión y desconocimiento. Las nociones de patrimonio nacional o de la humanidad siempre fueron problemáticas pero ahora, en este tiempo globalizador que difunde bienes y acontecimientos culturales de todos los continentes y acentúa las disputas entre patrimonios adversarios, entre actores públicos, privados y sociales, locales, nacionales y transnacionales, resultan todavía mucho más equívocas.

Los primeros estudios sobre la globalización (Beck, Robertson) subrayaron lo que hay en ella de interdependencia entre las naciones: una interdependencia que es asimétrica, selectiva y desigual. Hay algo más complejo que una fluida circulación de personas, 
capitales, bienes y mensajes entre todas las sociedades. En la gestión de las artes visuales por ejemplo, la administración de ferias y bienales siguen prevaleciendo Europa y los Estados Unidos pero crece la participación de países asiáticos.

En el mapa actual de esta división del trabajo cultural operan condicionamientos nacionales (el acceso no equitativo al desarrollo económico, tecnológico y educativo) y también las políticas regionales que expanden o aíslan a las culturas nacionales. Se trata de un mapa con muchos actores y procesos multidireccionales donde la mundialización de algunas localidades y el aislamiento de la mayoría se configura en interacciones entre estados, empresas privadas, migraciones y movimientos culturales, mediáticos y turísticos.

En definitiva, se reformula el estudio y la gestión del patrimonio no solo como conservación y consagración de piezas con valores extraordinarios, sino como participación en los dilemas cognitivos, éticos y sociopolíticos de la interculturalidad. La carencia de gobernabilidad mundial real y efectiva implica que la interdependencia abierta por la globalización va a estar contrariada por procesos de desglobalización: vemos atrincheramientos nacionales o regionales e invasiones en las que la conservación de los patrimonios históricos y artísticos así como la democratización del acceso a los bienes quedan agraviados o abolidos (Guerra de Irak en 2003).

\section{Reapropiaciones de los objetos: ¿arte, marketing o cultura?}

Según Canclini existen fuertes coincidencias entre los museos de arte y de antropología: en ambos se desarrollan desde hace años museografías polifónicas, narrativas múltiples en las que los objetos hablan con el sentido de quienes los fabricaron, de quienes los utilizan o perciben, los coleccionan o estudian. La ampliación de recursos audiovisuales y escenográficos ayuda a exponer y a combinar esos saberes y esas miradas.

Tanto los museos de arte, antropología o historia como los medios realizan ejercicios de poder al apropiarse de los objetos, seleccionarlos, situarlos en lugares más o menos prominentes, iluminarlos y editarlos en narrativas que congelan la proyección virtual de las tentativas y las reducen a obras. Las culturas visuales, ordenadas como colecciones y trofeos en el tiempo del colonialismo, jerarquizadas por la autenticidad de los objetos en cierta etapa de la antropología y de los orgullos nacionalistas pueden ser ahora un lugar para la comunicación y el diálogo intercultural. La pregunta aquí sería: ¿qué podemos comprender de los otros y cómo convivir con lo que no entendemos o no aceptamos?

Tal vez la traducción intercultural sea una función estratégica del arte en un tiempo de continuas interacciones globales: las políticas que se ocupan del patrimonio podrían asumir el sentido dinámico y experimental de la mirada artística y así además de almacenar y proteger podrían ampliar sus tareas a traducir y propiciar la formación de públicos flexibles, capaces de valorar bienes distintos y representativos de varias culturas. El patrimonio debería ser reconceptualizado: además de un repertorio de bienes se reconocerían repertorios de usos.

\section{Valorar el arte: entre mercado y política}

La práctica artística no inaugura el sentido, sino que recomienza o reinventa a partir de un patrimonio, de lo que ya está hecho, dicho y organizado en colecciones y discursos. Podemos dar un paso más allá y preguntarnos, según Canclini, ¿quiénes deciden qué prácticas artísticas nos gustan? Y en este punto señala que se atribuye el poder a 
individuos más que a las estructuras y a las instituciones: son determinantes las acciones de determinados artistas (Damien Hirst), galeristas (Larry Gagosian), coleccionistas (François Pinault), directores de museos, arquitectos y curadores (Hans Ulrich), que cuentan con un alcance transnacional. Asimismo, también hay que valorar el papel de las redes digitales en la orientación de la circulación de la información y la orientación de los inversores.

Por otro lado, el autor retoma las preguntas que se hizo Bourriaud en relación a las prácticas artísticas tan variadas que se dan en la actualidad. ¿Y es que cómo se puede elaborar una definición y un saber para este heterogéneo conjunto? Según Bourriaud, los artistas actúan ahora en el contexto de una sociedad concebida de modo abierto, de manera que entiende el arte como una actividad "que consiste en producir relaciones con el mundo con la ayuda de signos, formas, gestos y objetos”.

Canclini sugiere además acercarse a los estudios antropológicos pues, según él, son ellos los que mejor captan la diversidad interna del arte y sus vínculos externos. En concreto recoge la investigación de Sarah Thornton dirigida a captar la lógica actual de lo que ella sigue denominando "el mundo del arte", y que se basa en el principio de que el llamado campo artístico debe estudiarse en redes transnacionales. Pero esa escala global no es fácilmente aprehensible y ella misma apunta que el mundo contemporáneo del arte es una red dispersa de subculturas superpuestas por el simple hecho de que todas ellas creen en el arte. Para el autor, cuando la etnografía se detiene en la descripción no logra un relato que avance hacia conclusiones teóricas (algo que aprecia en la obra de Thornton) y por ello plantea que el reto pendiente es cómo pasar de la etnografía del mundo hegemónico del arte a algún tipo de conceptualización más amplia que lo sitúe en procesos sociales globalizados donde quizá encontremos más respuestas.

\section{Localizaciones inciertas}

En este capítulo el autor se acerca a varios artistas y sus obras, analizando cómo las hacen en una época que pretende ser posnacional, intermedial y es mal representada por grandes narrativas religiosas o políticas. Para ello, elige a tres artistas periféricos que han entrado por distintas vías en el mainstream y que pertenecen a una vasta corriente que concibe obras para que circulen tanto por la calle y la televisión como por las galerías y las bienales: Antoni Muntadas, Cildo Meireles y León Ferrari. Constata que en esta época de arte postautónomo los artistas rediseñan sus programas creativos para ubicarse flexiblemente en lo que queda de los campos artísticos y en otros espacios y redes.

Esta expansión de las prácticas modifica también los ámbitos de la teoría, la crítica y las políticas culturales, de manera que ahora el trabajo crítico se ve en la necesidad de reconcebir el papel del arte más allá de la museificación y la bienalización. Asimismo, se produce una redefinición análoga con la relación territorial establecida entre nación y arte, y con la concepción que llevó a escribir historias nacionales del arte: es necesario repensar la visibilidad y comunicabilidad de las artes sin caer en la deslocalización absoluta, ni en el mero regreso a la exaltación nacionalista. Las operaciones artísticas no pueden reconciliar al mundo anulando diferencias y desigualdades y tampoco pueden hacerse cargo de identidades nacionales o étnicas, sin asumir las grietas y las contradicciones.

Canclini apunta también la localización incierta de muchos procesos culturales en la actualidad: una idea que sintoniza con el cambio de la noción de lugar en la producción y la circulación digital de imágenes. La difusión digital reduce, aunque no elimina, la sacralización de lugares de exhibición como los museos y las bienales, y crea otros modos 
de acceso y socialización de las experiencias artísticas. Produce también una relativa homologación del arte con otras zonas de la cultura visual. Todo ello obliga a repensar la tarea de los museos como custodios que facilitan la comunicación de las obras que conservan, como una suerte de colecciones-archivos compartidos.

\section{Agonía de lo público y tácticas de sobrevivencia}

La teoría de los campos artísticos se formó en la época en la que concebíamos al mundo como moderno e integrado en un relato. Estos principios de organización social se fueron trasladando a un relato mundializado, de forma que se fue pasando de la solidaridad entre ciudadanos de una nación a la fantasía más reciente de una ciudadanía global. También se llega a las nuevas solidaridades corporativas de empresarios, empleados y consumidores que se identifican con la fábrica transnacional que vende una bebida o un coche en muchos países. La última etapa de esta narrativa es la de la solidaridad entre redes, posible gracias a las ONG, los sitios de Internet y a comunidades transnacionales de consumidores de música, ropa de marca o recursos para la salud física o espiritual.

En un tiempo en el que las cuestiones públicas de la cultura (las que tienen que ver con los derechos, el bienestar y el acceso de las poblaciones) quedan rezagadas bajo la hegemonía mercantil de empresas transnacionales, el desarrollo del arte ha pasado a depender de redes de galerías líderes con alto poder económico, museos, bienales y ferias. Su poder se concentra en algunos países del hemisferio norte, todos en competencia por vender y atraer inversores. Esta creciente apropiación de escenas públicas por parte de actores privados les otorga una enorme capacidad de rediseñar los espacios y los circuitos donde se informan y entretienen las mayorías, donde se acumulan los recursos, se configura el valor simbólico y la apreciación de las obras y las prácticas. Según Canclini, estamos ante un proceso de reestructuración e incluso de descomposición radical de lo público, con un extendido malestar y desorden social. Destaca dos rasgos estructurales de esta nueva situación:

1. El desmantelamiento de la oposición inclusión / exclusión: en la primera modernidad (desde la Ilustración hasta mediados del siglo XX), la sociedad era imaginada como una totalidad abarcable y con creciente integración de todos los sectores. El Estado sería el garante de esa inclusión y de la estructuración coherente de una sociedad cada vez más participativa. Al secularizarse la organización social y las prácticas personales se favorecieron las disidencias. Estos quiebros eran pensados como la renovación de un orden social que finalmente, a largo plazo, aparecía con continuidad. En el terreno artístico los conflictos entre el arte académico y las vanguardias también fueron concebidos como una disputa según la cual los participantes, por el hecho de intervenir, manifestaban su deseo de reproducir el campo renovando sus opciones de vida. Sin embargo, en la actualidad, muchos sectores no quieren ser incluidos o no se sienten parte de ningún proyecto nacional o social que trascienda los intereses de grupo. Suelen ver la inclusión como una oportunidad para aprovechar recursos. En la producción artística de las nuevas generaciones se aprecia el uso mixto de recursos incluyentes y otros informales, o aún ilegales.

2. El pasaje de las políticas de convivencia a las tácticas de supervivencia: el antropólogo Marc Abélès escribe que su generación (baby boomer) creía en alguna forma de progreso y equilibrio después del terror, pero a principios del siglo XXI observa que hemos cambiado nuestra relación con la política al pasar de una tradición que considera la convivencia (entendida como el estar juntos) como el objetivo prioritario, a una etapa en la que la preocupación por la supervivencia orienta las elecciones en el espacio público. 
Esta situación está motivada según Canclini por dos causas fundamentales: en primer lugar, cita el cambio de escala que trajo la globalización, tanto en las expectativas, en la capacidad de identificar los orígenes de los problemas como en las maneras de reunirse; y en segundo lugar, plantea que también cambió nuestra visión del futuro y de la política el ejercicio opaco y anónimo de las instancias donde se condensa el poder. Mientras que aumenta la opacidad del poder, los ciudadanos-consumidores somos cada vez más transparentes porque los sistemas de vigilancia social saben lo que comemos, donde compramos así como las reacciones al malestar político. Este carácter misterioso de la actual estructura de poder es quizá, según el autor, el principal motivo de la impotencia ciudadana y el desinterés por la política. Antes se atribuía al estado la tarea de controlar la inseguridad pero el aumento de la precariedad y la incertidumbre han hecho de la supervivencia la preocupación central.

En el campo de las artes visuales se quebró la secuencia París - Londres - Nueva York. Ya no hay una capital del arte sino que ahora varias ciudades concentran el poder y lo movilizan en distintas direcciones. Esta distribución compleja e inestable de focos en los que se ejerce el poder se aprecia ya en cualquier ámbito, no solo en el artístico. Esta dispersión genera el primer problema para construir resistencias, oposiciones o alternativas. Artistas como Santiago Sierra, Antoni Muntadas o León Ferrari realizan obras y performances interpretables en este marco, reinventan su lenguaje para hablar de un mundo contradictorio y en descomposición pero lo hacen enfrentando relatos todavía identificables. Otros artistas como por ejemplo, Carlos Amorales, no incorporan en sus obras un relato social o político identificable. Sus trabajos sugieren a la vez descomposición, incertidumbre siniestra y una perturbadora vitalidad o serenidad (Dark Mirror (From The bad sleep well 03), México, 2007).

\section{Cómo hace sociedad el arte}

Espectáculo - espectacularización - espectador: esta secuencia es, según el autor, protagonista en el marco de los procesos artísticos. Los proyectos creativos acaban de realizarse en el reconocimiento de quienes los ven. Desde esta perspectiva, la pregunta ya no es qué es el arte sino qué puede hacer.

El giro al receptor no es solo un cambio endógeno del arte: es el resultado del cuestionamiento a las instituciones culturales, la crítica a la economía capitalista y el autoritarismo político. Esta inclusión de los públicos implica una reflexión sobre su actividad y es que ya no son siempre consumidores sino también partícipes en la producción o prosumidores. En un tiempo en que cualquiera puede generar y difundir imágenes en su teléfono móvil y difundirlas a través de los diversos mecanismos de la web 2.0, es fundamental repensar qué se entiende por espacio y circuito público, cómo se forman las comunidades interpretativas y creadoras y otros modos de establecer pactos de lectura, comprensión, sensibilidad y acción. La expansión del arte fuera de su campo, la democratización de las relaciones sociales y la reutilización económica, política o mediática de los trabajos artísticos ha llevado a los artistas y a los espectadores a vivir en zonas de intersección.

En este contexto la innovación artística interactúa con la comprensión y la incomprensión de los públicos, con los rechazos institucionales o los intentos institucionales de asimilarlos, pero ya no hay fronteras claras ni duraderas.

La inminencia que postula Canclini no es un estado místico de contemplación de lo inefable sino que es una disposición dinámica y crítica. Ante el desorden del mundo sin 
relato unificador surge la tentación de retroceder a comunidades armoniosas donde cada uno ocupe su lugar en su etnia, su clase o en un campo artístico idealizado. La espectacularización ofrecida por los medios y por exhibiciones artísticas obedientes a las reglas del espectáculo se dedica a neutralizar el disenso social o a convencernos de que algún poder mágico-político puede evitarlo. Las acciones artísticas ensayan salidas de este hechizo a través de distintos modelos y concluye el autor que apuntan así a crear un paisaje inédito de lo visible, nuevas subjetividades y conexiones, ritmos diferentes de aprehensión de lo dado.

\section{Epílogo}

En definitiva, este libro parte del vacío que dejó el agotamiento de la/s estética/s moderna/s, pero sin pretender desembocar en una nueva estética. No establece una normativa sobre el arte que debe hacerse sino que describe el paisaje actual de esta práctica observando lo que sucede en algunos talleres, obras, museos, subastas, públicos, teorías y críticas del arte. Canclini extrae algunas conclusiones de circuitos en los que el arte se abre a vínculos que están más allá de su campo y constata que esa apertura, así como los estímulos de actores externos, vuelven problemática la autonomía del mundo artístico. Le interesa especialmente comprender los cambios en la actuación de los artistas y demás participantes del campo, la construcción de redes que desbordan los campos y sus comportamientos variables. Selecciona y analiza algunos artistas y sus obras, no para formar un canon sino un corpus documental.

No hay teorías generales que abarquen la actual diversidad de las prácticas artísticas y ante este panorama, las estéticas posibles son las que aceptan lo intempestivo. Por su parte, la sociología del arte se vuelve etnografía de un paisaje de interacciones culturales que se altera una y otra vez. Estamos en la inminencia y llamamos arte a las maneras de trabajar en ese umbral, no para ingresar en un territorio sino para describir una tensión. No es posible arribar a una teoría general del arte porque las prácticas de los artistas y de las instituciones no son sumables bajo una sola lógica.

Se cayeron los relatos de la modernidad pero tampoco son convincentes las ilusiones vanguardistas del posmodernismo. No hay un relato para la sociedad globalizada que articule sin conflictos o desfases los desacuerdos disciplinarios, sociales e interculturales. En esta coyuntura, considera Canclini que el arte que trabaja con la inminencia se ha mostrado fecundo para elaborar una pregunta distinta: ¿qué hacen las sociedades con aquello para lo que no encuentran respuesta en la cultura, la política y la tecnología? El arte hace sociedad: lo logra cuando pretende pensar y acompañar la recomposición de las estructuras, interacciones y experiencias. En este punto el autor afirma que es indispensable para rehacer la teoría, una teoría abierta al desorden social, sin gran relato único, la exigencia antropológica de escuchar a los actores, a los más diversos y detenerse en lo cualitativo y en la densidad de los hechos.

¿Qué es lo que puede llegar? Una estética de la inminencia no es una estética de lo efímero, es una disposición a lo que puede llegar, una apertura a lo desconocido y un modo no patrimonialista de trabajar con la sensibilidad. La tarea del arte no es darle un relato a la sociedad para organizar su diversidad, sino valorizar lo inminente donde el disenso es posible. Además de ofrecer iconografías para la convivencia o manifiestos para las rupturas, los artistas pueden participar reimaginando los desacuerdos.

Quizá haya una ética para esta estética sin relato. No se formaría armonizando patrimonios de culturas discrepantes sino acompañando a los agentes fusionadores que 
son los migrantes o los disidentes o los extranjeros en su propia sociedad. Para Canclini, los artistas, los curadores, los críticos y los públicos podemos ser comunidades o redes gozadoras de lo que se anuncia.

Elvira Calle Sánchez

Licenciada en Historia del Arte, Universitat de València

Máster en Gestión del Patrimonio Cultural, Universidad de Zaragoza

Gestión de colecciones en museos (España y Reino Unido) y proyectos arquitectónicos

(Foster and Partners, Londres) 